\title{
A novel substitution I381V in the sterol $14 \alpha$-demethylase (CYP51) of Mycosphaerella graminicola is differentially selected by azole fungicides
}

\author{
B. A. FRAAIJE ${ }^{1 *}$, H. J. COOLS 1 , S-H. KIM², J. MOTTERAM ${ }^{1}$, W. S. CLARK ${ }^{3}$ AND J. A. LUCAS ${ }^{1}$ \\ ${ }^{1}$ Rothamsted Research, Plant-Pathogen Interactions Division, Harpenden, Hertfordshire AL5 2JQ, UK \\ ${ }^{2}$ Alpine Medicinal Plant Research Station, Bonghwa 755 843, South Korea \\ ${ }^{3}$ ADAS Boxworth, Cambridge CB3 8NN, UK
}

\section{SUMMARY}

The recent reduction in the efficacy of azole fungicides in controlling Septoria leaf blotch of wheat, caused by Mycosphaerella graminicola, has prompted concerns over possible development of resistance, particularly in light of the recent emergence of widespread resistance to quinone outside inhibitors (Qols). We have recently implicated alterations in the target-encoding sterol $14 \alpha$-demethylase protein (CYP51), and over-expression of genes encoding efflux pumps, in reducing sensitivity to the azole class of sterol demethylation inhibitors (DMIs) in M. graminicola. Here we report on the prevalence and selection of two CYP51 alterations, substitution I381V and deletion of codons 459 and 460 ( $\triangle Y 459 / G 460$ ), in populations of $M$. graminicola. Neither alteration has previously been identified in human or plant pathogenic fungi resistant to azoles. The presence of $\triangle \mathrm{Y} 459 / \mathrm{G} 460$ showed a continuous distribution of $\mathrm{EC}_{50}$ values across isolates with either I381 or V381, and had no measurable effect on azole sensitivity. Data linking fungicide sensitivity with the presence of I381V in M. graminicola show for the first time that a particular CYP51 alteration is differentially selected by different azoles in field populations of a plant pathogen. Substitution I381V although not an absolute requirement for reduced azole sensitivity, is selected by tebuconazole and difenoconazole treatment, suggesting an adaptive advantage in the presence of these two compounds. Prochloraz treatments appeared to select negatively for I381V, whereas other azole treatments did not or only weakly impacted on the prevalence of this substitution. These findings suggest treatments with different members of the azole class of fungicides could offer a resistance management strategy.

\footnotetext{
*Correspondence: E-mail: bart.fraaije@bbsrc.ac.uk
}

\section{INTRODUCTION}

Septoria leaf blotch, caused by the ascomycete Mycosphaerella graminicola (anamorph Septoria tritici), is the most important foliar disease of winter wheat in the UK (Hardwick et al., 2001), causing estimated annual yield losses of $\mathrm{f} 30$ million. Current commercial wheat cultivars are susceptible or only partially resistant to the disease in the UK. Since the late 1970s control has depended mainly on the programmed application of fungicides. The most active control agents are target site-specific systemic fungicides, which include the methyl benzimidazole carbamates (MBCs), sterol demethylation inhibitors (DMIs) and quinone outside inhibitors (Qols). However, resistance to these fungicide groups has evolved in M. graminicola. In the mid 1980s, resistance to MBC fungicides, caused by a point mutation in the target encoding $\beta$-tubulin gene resulting in substitution of a glutamic acid for an alanine residue at codon 198 (E198A), emerged and remains widespread in M. graminicola populations today (B. A. Fraaije, unpublished data). Resistance to the Qol fungicides in $M$. graminicola populations, also caused by a mutation in the target gene [replacing an alanine for glycine at position 143 (G143A) of the mitochondrial cytochrome $b$ ], was first detected in the UK in 2002 and has since compromised disease control despite measures implemented to reduced selection for resistance (Fraaije et al., 2003, 2005a). Resistance to the azole fungicides has yet to emerge in M. graminicola populations, although recent studies have demonstrated an erosion of efficacy and higher doses are now required to achieve effective disease control (Gisi et al., 2004). Together, these studies have prompted concerns that further shifts in azole sensitivity might compromise disease control.

Azole fungicides have a single biochemical target, the sterol $14 \alpha$-demethylase (CYP51), an essential enzyme in the biosynthetic pathway of ergosterol, the predominant sterol in plasma membranes of most fungi. However, unlike most site-specific fungicides, where a single mutation can confer a highly resistant phenotype, azole resistance often emerges as a result of multiple resistance mechanisms. Alterations in sterol biosynthesis, the 
target site, and fungicide uptake and efflux have all been identified as resistance mechanisms (Joseph-Horne and Hollomon, 1997). For example, in the opportunistic human pathogen Candida albicans, which can cause serious clinical problems in immunocompromised patients, strains highly resistant to azoles commonly carry several mutations in the CYP51 gene and also over-express efflux pumps of the ATP-binding cassette (ABC) or major facilitator (MF) transporter superfamilies (Perea et al., 2001). The location, frequency and impact of CYP51 mutations have been extensively studied in C. albicans (Marichal et al., 1999). Functional analysis in Saccharomyces cerevisiae of mutations identified in resistant isolates of $C$. albicans demonstrated four mutations (Y132H, S405F, G464S and R467K) that affect azole sensitivity both as single mutations, and to a greater extent when combined (Sanglard et al., 1998), demonstrating that different CYP51 mutations as well as different mechansims can combine to confer a step-wise increase in resistance.

Understanding of the mechanisms underlying altered azole sensitivity in plant pathogens is more limited, primarily as resistance has developed relatively slowly without to date affecting practical disease control. The amino acid substitution Y136F, equivalent to residue Y132 in C. albicans, has been associated with azole resistance in Uncinula necator (Delye et al., 1997), and Blumeria graminis (Delye et al., 1998). Recent studies on $B$. graminis f. sp. hordei using crosses between azole-sensitive and azole-resistant isolates demonstrated resistance-linked segregation of CYP51 substitutions, Y136F and K147Q, although it was also suggested that these mutations were not the sole determinants of the resistant phenotype (Wyand and Brown, 2005). Other CYP51 substitutions have been reported for Oculimacula spp. but their exact contribution to azole insensitivity has yet to be established (Albertini et al., 2003). In Penicillium digitatum (Hamamoto et al., 2000) Venturia inaequalis (Schnabel and Jones, 2000) and V. nashicola (Cools et al., 2002), CYP51 mutations were not identified, but alternative mechanisms, including over-expression of the target gene, correlated with reduced azole sensitivity.

In laboratory-generated mutants of M. graminicola (Zwiers et al., 2002) and field isolates (Stergiopoulos et al., 2003) obtained in the mid 1990s, reduced azole sensitivity was associated with enhanced efflux and, in some isolates, CYP51 gene over-expression, with no CYP51 mutations reported. However, several CYP51 alterations were recently identified in field isolates with reduced sensitivity to azoles, along with up-regulation of genes encoding efflux proteins (Cools et al., 2005a). Interestingly, Y137F, equivalent to codon 132 in C. albicans, was not associated with azole resistance, whereas combinations of alterations [e.g. I381V, Y459D, Y461H and a 6-bp deletion covering codons 459 and 460 ( $\triangle \mathrm{Y} 459 / \mathrm{G} 460)$ )] were linked to reduced triazole sensitivities (Cools et al., 2005b). Recently, Zhan et al. (2006) reported high levels of azole resistance and high frequencies of CYP51 alterations, involving codons 459-461, in M. graminicola populations sampled in Switzerland, Germany and England and suggested that this was due to intensive use of azoles on cereals in this part of Europe.

The objective of this study was to determine the incidence, prevalence and selection by different azoles of CYP51 alterations I381V (exchange of isoleucine for valine at codon 381) and $\triangle Y 459 / G 460$ in isolates and populations of $M$. graminicola, using selection of the Qol resistance conferring cytochrome $b$ G143A allele as a comparison. Data obtained from fungicide sensitivity assays and quantitative allele-specific PCR measuring the frequency of I381V show for the first time in a population of a fungal pathogen that a specific change in the CYP51 target site protein is differentially selected by members of the azole class of fungicides.

\section{RESULTS}

\section{Fungicide sensitivity profiles of $\boldsymbol{M}$. graminicola populations}

Cumulative distribution patterns of isolate $\mathrm{EC}_{50}$ values in M. graminicola populations sampled at Rothamsted Research in 2003, 2004, 2005 and 2006 were distinct between azoxystrobin, epoxiconazole and tebuconazole (Fig. 1). In 2003, isolates fell into two distinct subpopulations in relation to azoxystrobin sensitivity with $\mathrm{EC}_{50}<0.2 \mathrm{mg} / \mathrm{L}$ and $>0.9 \mathrm{mg} / \mathrm{L}$, forming a bimodal distribution commonly associated with single gene-mediated resistance. In comparison with 2003 , where $40 \%$ of the isolates were highly resistant showing $\mathrm{EC}_{50}$ values $>0.9 \mathrm{mg} / \mathrm{L}$, the resistant subpopulation was further selected in subsequent years, culminating in a population containing $96 \%$ of highly resistant isolates in 2006. The distribution of epoxiconazole and tebuconazole sensitivities of $M$. graminicola isolates in the Rothamsted populations was more continuous within years (Fig. 1B,C). A shift in sensitivity to epoxiconazole occurred between 2003 and 2004 with the median $\mathrm{EC}_{50}$ value increasing from 0.13 to $0.22 \mathrm{mg} / \mathrm{L}$. Although no further significant increase in median $\mathrm{EC}_{50}$ was measured in either $2005(0.24 \mathrm{mg} / \mathrm{L})$ or $2006(0.23 \mathrm{mg} / \mathrm{L})$, the mean $\mathrm{EC}_{50}$ increased from $0.28 \mathrm{mg} / \mathrm{L}$ in 2004 to $0.52 \mathrm{mg} / \mathrm{L}$ in 2005 , whereas in 2006 a $\mathrm{EC}_{50}$ value of $0.44 \mathrm{mg} / \mathrm{L}$ was measured. The $\mathrm{EC}_{50}$ distribution pattern of tebuconazole was similar to that for epoxiconazole. There was a clear shift in sensitivity to tebuconazole between 2003 and 2004, with median and mean $\mathrm{EC}_{50}$ values increasing from 0.85 to $2.95 \mathrm{mg} / \mathrm{L}$ and 1.11 to $2.73 \mathrm{mg} / \mathrm{L}$, respectively. No significant further increase in median and mean $\mathrm{EC}_{50}$ was measured in 2005 (2.58 and $2.67 \mathrm{mg} / \mathrm{L})$ and 2006 (3.12 and $3.02 \mathrm{mg} / \mathrm{L})$.

\section{Detection of CYP51 I381V and $\triangle$ Y459/G460 alterations in populations and isolates of M. graminicola}

Detection of substitution I381V in M. graminicola isolates was highly specific (Fig. 2A,B). Within 40 PCR cycles, no fluorescent 

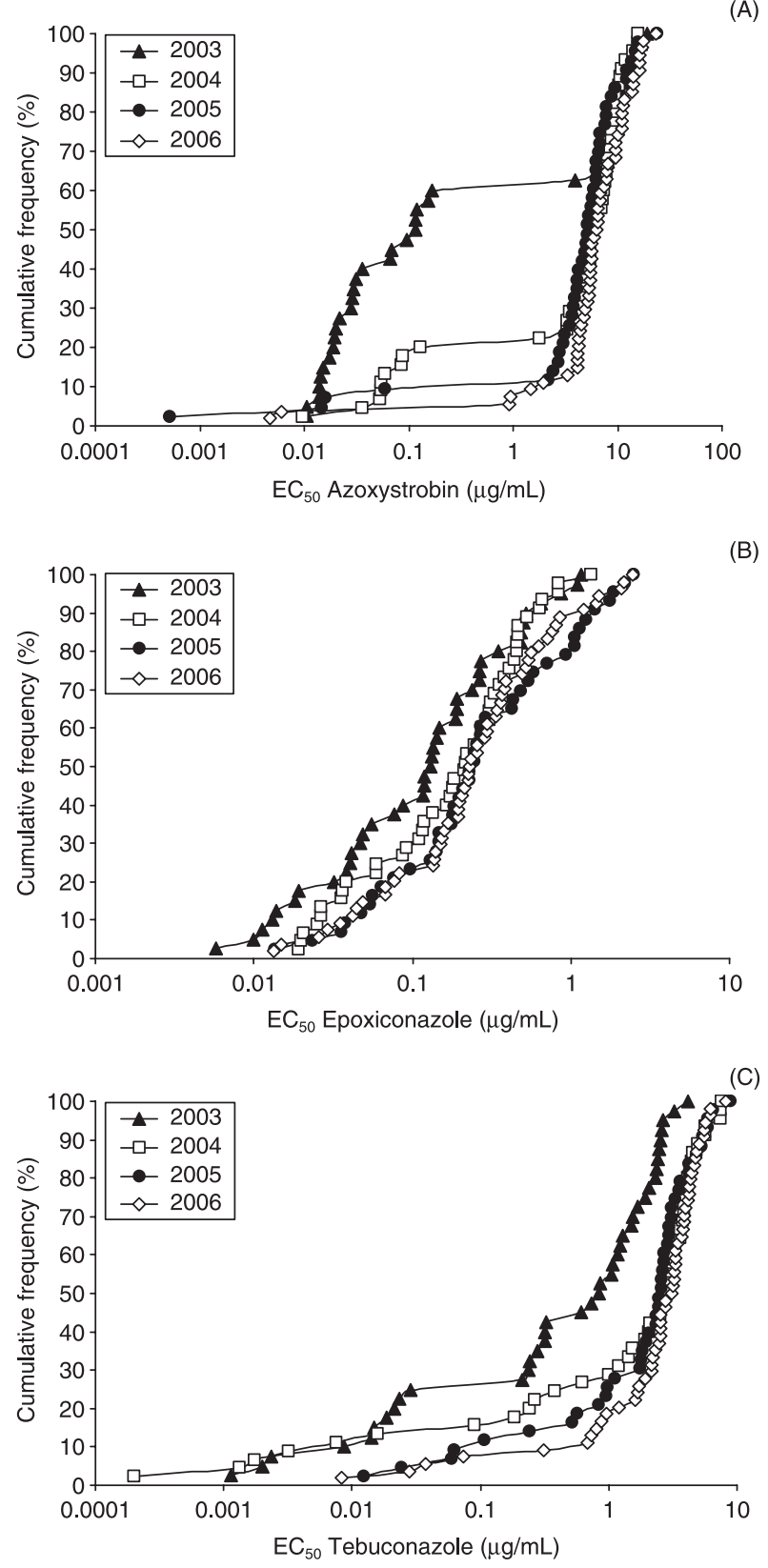

Fig. 1 Sensitivity of $M$. graminicola isolates to azoxystrobin (A), epoxiconazole (B) and tebuconazole (C) at Rothamsted between 2003 and 2006. Isolates grouped according to increasing $\mathrm{EC}_{50}$ values (cumulative).

signals were measured for DNA extracted from Triticum aestivum (wheat), Blumeria graminis f. sp. tritici, Fusarium graminearum, Oculimacula yallundae, Puccinia striiformis, Rhizoctonia cerealis, Rhynchosporium secalis and Stagonospora nodorum. Inclusion of a third Cy5-labelled probe in the assay, St381uni (Table 1), facilitated determination of fluorescent signal ratios and subsequent calculation of I381V frequencies in population samples (data not shown). Detection of Y459/G460 and, in particular, $\triangle Y 459 / G 460$ was not specific enough due to crossreactivity (Fig. $2 C, D$ ), making determination of frequencies of this deletion in population samples impossible. The assay could, however, be used to screen isolates for absence or presence of $\Delta \mathrm{Y} 459 / \mathrm{G} 460$. With regard to MGB probe specificity, no differences in signal intensity were observed between $M$. graminicola isolates carrying substitutions Y459D, G460D or Y461H and isolates carrying wild-type CYP51 (Y459/G460/Y461) (data not shown).

\section{Relationship between isolate azoxystrobin, epoxiconazole and tebuconazole sensitivity and cytochrome b substitution G143A}

The prevalence of substitution G143A in M. graminicola isolates in the 2003, 2004, 2005 and 2006 Rothamsted population was plotted against isolate sensitivity to azoxystrobin, epoxiconazole and tebuconazole (Fig. $3 \mathrm{~A}-\mathrm{C}$, respectively). All isolates with A143 alleles had azoxystrobin $\mathrm{EC}_{50}$ values $>0.9 \mathrm{mg} / \mathrm{L}$ whereas isolates carrying the $\mathrm{G} 143$ allele showed $\mathrm{EC}_{50}$ values $<0.2 \mathrm{mg} / \mathrm{L}$ (Fig. 3A). No clear relationship between the presence of G143A and sensitivity to epoxiconazole and tebuconazole was apparent, with a continuous distribution of $\mathrm{EC}_{50}$ values across isolates with either allele (Fig. 3B). Interestingly, isolates with the highest $\mathrm{EC}_{50}$ values for both epoxiconazole and tebuconazole carried A143 alleles, but this might be due to the fact that isolates carrying G143 alleles have become rare in the populations sampled after 2003. In 2006, $96 \%$ of the isolates tested carried A143 alleles (Table 2).

\section{Relationship between isolate azoxystrobin, epoxiconazole and tebuconazole sensitivity and CYP51 alterations I381V and $\triangle$ Y459/G460}

The frequency of isolates carrying the 1381V substitution increased between 2003 and 2004, with frequencies of 40 and $60 \%$, respectively, stabilizing in 2005 and 2006 (Table 2). Interestingly, a high proportion of isolates (between 89 and $94 \%$ ) carrying the I381V also carried G143A. The frequency of isolates carrying the $\triangle \mathrm{Y} 459 / \mathrm{G} 460$ was much lower, between 15 and $29 \%$, with no clear selection of this alteration over time being evident (Table 2). Figure 4 shows the association between different CYP51 alterations and fungicide sensitivities. Isolates carrying I381V and/or $\triangle \mathrm{Y} 459 / \mathrm{G} 460$ showed a continuous distribution of $\mathrm{EC}_{50}$ values for azoxystrobin and epoxiconazole (Fig. $4 \mathrm{~A}, \mathrm{~B}$ ). Isolates with $1381 \mathrm{~V}$ followed the same trend, but, interestingly, isolates with both $\mathrm{I} 381 \mathrm{~V}$ alleles and $\triangle \mathrm{Y} 459 / \mathrm{G} 460$ were also carrying G143A and, thus, highly resistant to azoxystrobin with $\mathrm{EC}_{50}$ values $>0.9 \mathrm{mg} / \mathrm{L}$. Generally, the majority of $\mathrm{I381}$ isolates, 48 out of 75 isolates tested, were more sensitive to tebuconazole than 

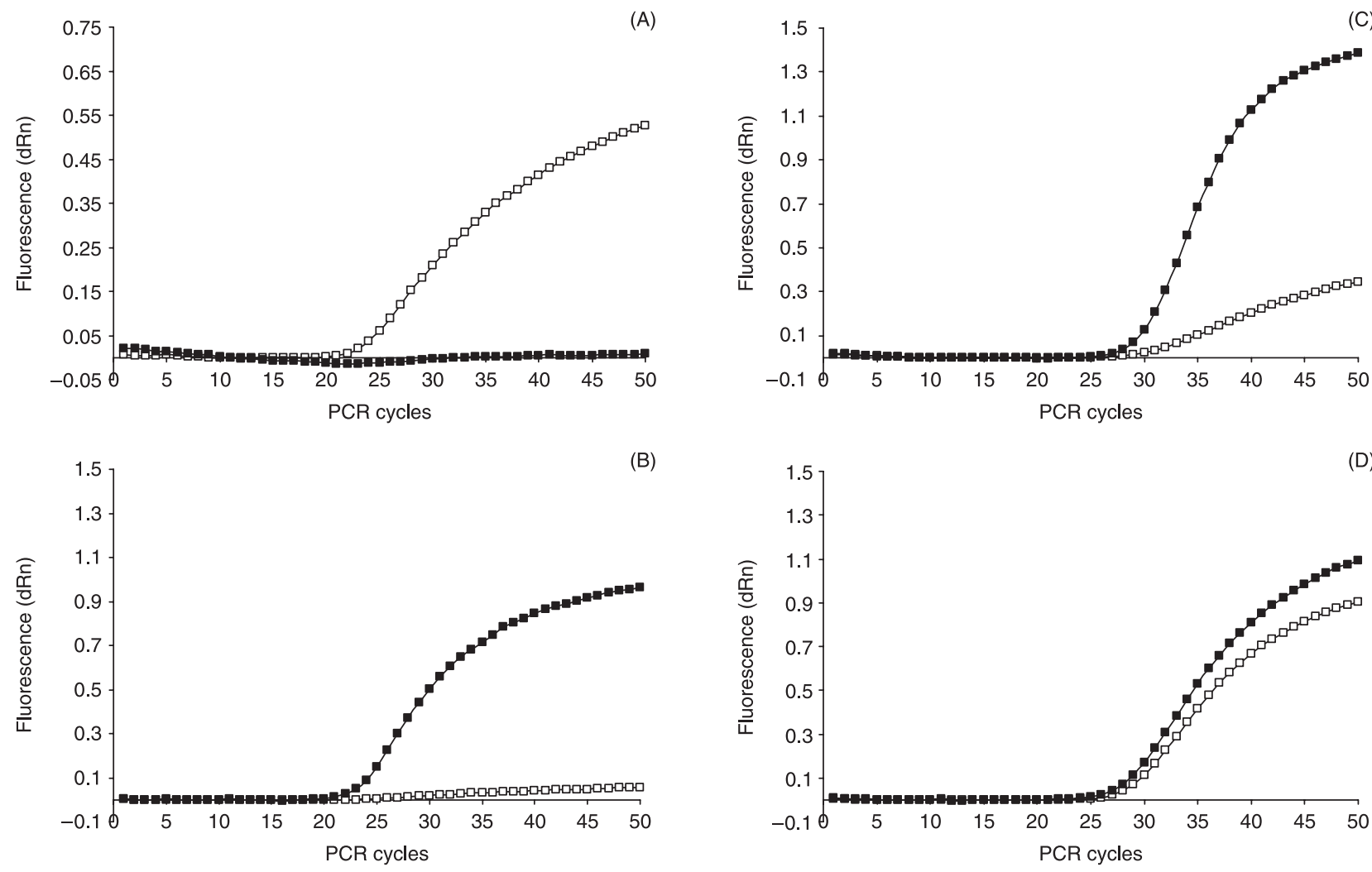

Fig. 2 Allele-specific PCR signals generated from M. graminicola isolates carrying exclusively CYP51 I381 (A), V381 (B), Y459/G460 (C) and $\Delta$ Y459/G460 (D) alterations. Solid and open squares represent levels of FAM and VIC fluorescence, respectively.

Table 1 Overview of oligonucleotides used in this study.

\begin{tabular}{|c|c|c|c|c|}
\hline Oligonucleotide name & Type* & Oligonucleotide Sequence and labelling $\left(5^{\prime}-3^{\prime}\right) \dagger$ & $(\mu \mathrm{m})$ & Concentration Target (allele) \\
\hline Stbf1 & Forward primer & ACATTAACATGAACAATCGGTACTATAATACTAG & 0.5 & Cytochrome b \\
\hline Stbr1 & Reverse primer & GGATTTCCTGAACCCGCTG & 0.3 & Cytochrome b \\
\hline Stcbuni & Probe & Cy5-AATGCAGCTAACACAAACGGTAAAACGA-BHQ-2 & 0.1 & Cytochrome b \\
\hline Stcbwt & MGB probe & FAM-CTGTTGCTCCTCATAA & 0.1 & Cytochrome b (G143) \\
\hline Stcbmt & MGB probe & VIC-TTGCTGCTCATAAAG & 0.1 & Cytochrome b (A143) \\
\hline St381f & Forward primer & GCCAACCTCTCGAAACTCAC & 0.4 & CYP51 \\
\hline St381r & Reverse primer & TGGGTGGTTGGAATGACGTA & 0.4 & CYP51 \\
\hline St381uni & Probe & Су5-CTCCTCAATCAAGTCGTCAAAGAAACCCTTC-BHQ-2 & 0.2 & CYP51 \\
\hline St381wt & MGB probe & VIC-AATGGAGTGGATTGGA & 0.25 & CYP51 (I381) \\
\hline St381mt & MGB probe & FAM-AATGGAGTGGACTGGA & 0.075 & CYP51 (V381) \\
\hline Stcpf1 & Forward primer & GACGACTGCCCTAGGAAGCAT & 0.5 & CYP51 \\
\hline Stcpr 1 & Reverse primer & CGCGCCCTTGCTTACAA & 0.5 & CYP51 \\
\hline Stcpwt & MGB probe & FAM-CATAGTCTTCTTTCTCC & 0.06 & CYP51 (Y459/G460) \\
\hline Stcpdel & MGB probe & VIC-CCGTAGTCTTCTTTCT & 0.2 & CYP51 ( $\triangle$ Y459/G460) \\
\hline
\end{tabular}

${ }^{*}$ MGB, Minor Groove Binder probe (see Afonina et al., 1997).

TFAM (6-carboxy-fluorescein), VIC and Cy5 are fluorescent labels; BHQ-2 is a dark Black Hole Quencher.

the mutant V381 isolates, where only five out of 107 isolates tested had tebuconazole $\mathrm{EC}_{50}$ values $<1.0 \mathrm{mg} / \mathrm{L}$ (Fig. 4C). $\triangle Y 459 / G 460$ was continuously distributed across isolate $E C_{50}$ values irrespective of $1381 \mathrm{~V}$ and therefore had no effect on tebuconazole sensitivity.

\section{Prevalence of I381V in untreated and fungicide-treated leaf populations sampled during 2001-06}

The frequency of $1381 \mathrm{~V}$ measured in population samples increased from $20.6 \%$ in 2001 to $56.7 \%$ in 2006 (Table 3). These 

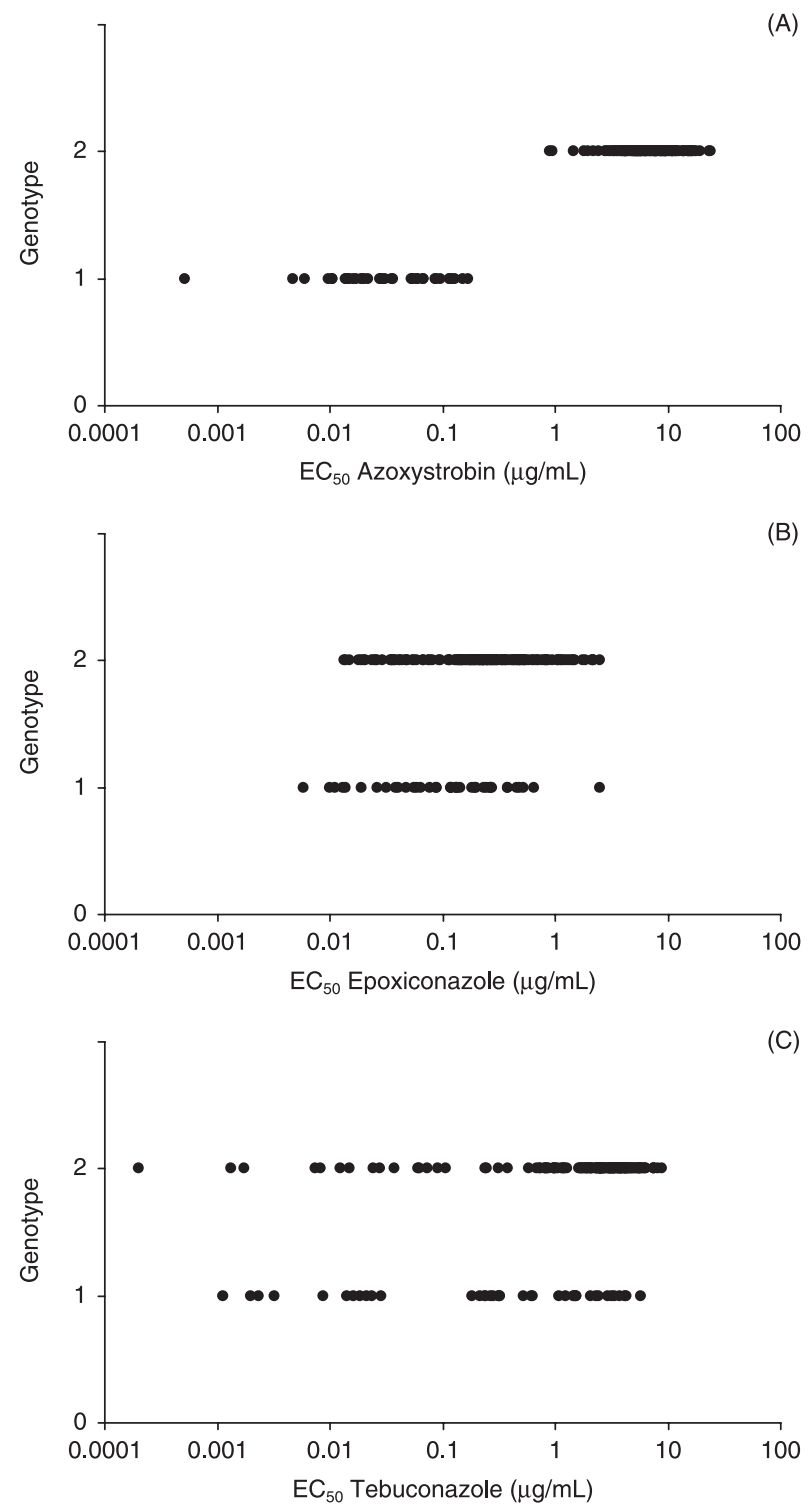

Fig. 3 Distribution of the cytochrome $b$ G143A across $E_{50}$ values of M. graminicola isolates in Rothamsted populations to azoxystrobin (A), epoxiconazole (B) and tebuconazole (C). Genotypes 1 and 2 represent, respectively, $\mathrm{G} 143$ and $\mathrm{A} 143$ alleles. results corresponded well with the values obtained for testing of isolates derived from the same samples (Table 2). The largest increase in 1381V frequency was measured between 2003 (27.7\%) and 2004 (48.1\%). Selection was evident after tebuconazole treatment with $1381 \mathrm{~V}$ frequencies increasing from 20.6 to $62.8 \%$ and 25.2 to $86.8 \%$ in 2001 and 2002 , respectively. Decreased sensitivity for tebuconazole in the presence of I381V agreed well with the results obtained in isolate $\mathrm{EC}_{50}$ testing where $95 \%$ of isolates carrying this substitution had values $\geq 1.0 \mathrm{mg} / \mathrm{L}$ (Fig. 4C). No increase in I381V frequency was measured for fluquinconazole-treated populations, and frequencies were only slightly raised in populations exposed to epoxiconazole in 2001 (23.7\%) and 2002 (36.9\%).

In 2006, M. graminicola populations were exposed to 12 different DMI fungicides at three different locations (Fig. 5). For all three locations a similar pattern of selection for I381V was observed. The selection was clearest in the Somerset population (Fig. 5A) where the lowest I381V frequency between locations $(63 \%)$ was measured in untreated plots. I381V frequencies in untreated populations sampled in Herefordshire (Fig. 5B) and Norfolk (Fig. 5C) were 75 and $82 \%$, respectively, Both positive and negative selection for $1381 \mathrm{~V}$ was observed in treated populations. For all locations, clear positive selection for I381V was measured in populations treated with the triazoles difenoconazole and tebuconazole, resulting in allele frequencies $>90 \%$. A weaker positive selection was observed for metconazole and tetraconazole. Negative selection for I381V in the populations sampled was most prominent and consistent after application of the imidazole prochloraz. In comparison with untreated plots, the largest decrease in I381V frequency was measured in Somerset, with frequencies of 63 and $34 \%$ in untreated and prochloraz treated plots, respectively.

\section{Relationship between isolate prochloraz sensitivity and I381V}

The negative selection for substitution I381V in M. graminicola populations upon treatment with prochloraz observed in the 2006 field trials was further examined using isolate $\mathrm{EC}_{50}$ testing.

Table 2 Prevalence of different cytochrome $b$ and CYP51 alterations in M. graminicola populations sampled at Rothamsted.

\begin{tabular}{|c|c|c|c|c|c|c|c|}
\hline \multirow[b]{2}{*}{ Population* } & \multicolumn{7}{|c|}{ Number of isolates carrying single and/or multiple cytochrome b/CYP51 alterations $†$} \\
\hline & I381V & G143A & $\Delta 459 / 460$ & $\begin{array}{l}\text { I381V and } \\
\text { G143A }\end{array}$ & $\begin{array}{l}\text { I381V and } \\
\Delta 459 / 460\end{array}$ & $\begin{array}{l}\text { I381V and G143A } \\
\text { and } \Delta 459 / 460\end{array}$ & $\begin{array}{l}\text { G143A and } \\
\Delta 459 / 460\end{array}$ \\
\hline $2003(n=40)$ & 16 & 16 & 6 & 12 & 3 & 3 & 3 \\
\hline $2004(n=45)$ & 27 & 36 & 13 & 26 & 6 & 10 & 6 \\
\hline $2005(n=43)$ & 28 & 39 & 5 & 25 & 3 & 5 & 3 \\
\hline $2006(n=54)$ & 36 & 52 & 10 & 34 & 8 & 10 & 8 \\
\hline
\end{tabular}

*Populations with the number of isolates $(n)$ tested in parentheses.

†lsolate alterations (cytochrome $b$ G143A and CYP51 I381V and $\Delta 459 / 460$ ) were detected with allele-specific real-time PCR. 


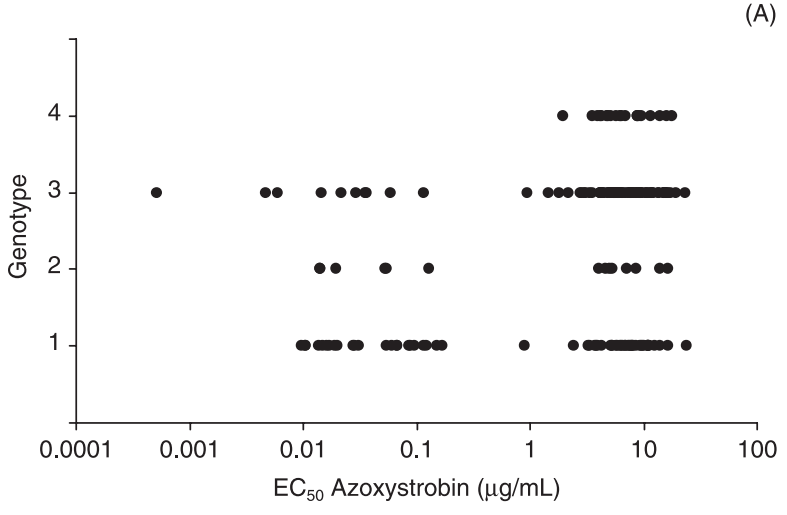

(B)

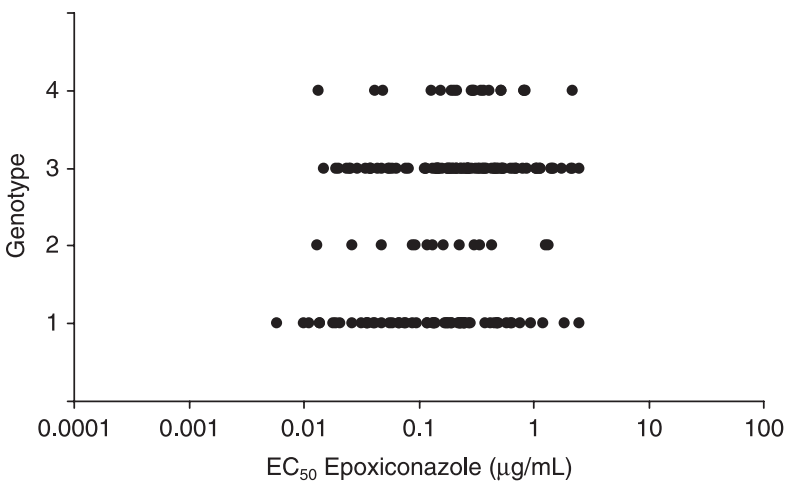

(C)

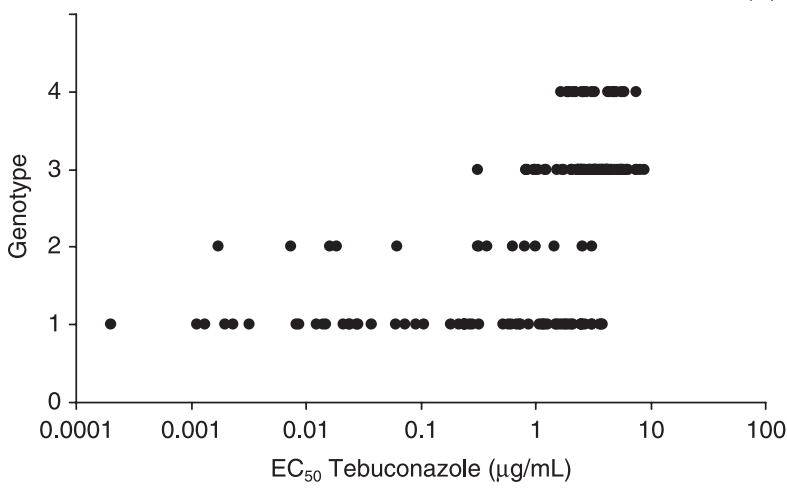

Fig. 4 Distribution of the I381V and $\triangle$ Y459/G460 CYP51 alterations across $E C_{50}$ values of $M$. graminicola isolates in Rothamsted populations to azoxystrobin (A), epoxiconazole (B) and tebuconazole (C). Genotype 1 represents presence of I381, genotype 2: 1381 and $\Delta \mathrm{Y} 459 / \mathrm{G} 460$, genotype 3: V381 and genotype 4:V381 and $\Delta Y 459 / G 460$ CYP51 alterations, respectively.

Figure 6 shows the results for Rothamsted 2006 isolates ( $n=54$ ). As expected, most of the isolates carrying $1381 \mathrm{~V}$ were more sensitive to prochloraz, with 25 out of 36 isolates having $\mathrm{EC}_{50}$ values $\leq 0.1 \mathrm{mg} / \mathrm{L}$. This is in sharp contrast to isolates not carrying this alteration, with 17 out of 18 showing an $\mathrm{EC}_{50}>0.1 \mathrm{mg} / \mathrm{L} . \Delta \mathrm{Y} 459$ / G460 again showed a continuous distribution of $\mathrm{EC}_{50}$ values across isolates irrespective of $1381 \mathrm{~V}$, and therefore had no obvious effect on prochloraz sensitivity (data not shown).
Table 3 Frequency of I381V in azole-treated and untreated M. graminicola populations sampled at Rothamsted.

\begin{tabular}{llll}
\hline Cultivar & Year & Treatment & I381V frequency* \\
\hline Riband & 2001 & Untreated & $20.6 \pm 0.3$ \\
Riband & 2001 & Epoxiconazole & $23.7 \pm 0.4$ \\
Riband & 2001 & Fluquinconazole & $17.3 \pm 3.9$ \\
Riband & 2001 & Tebuconazole & $62.8 \pm 0.8$ \\
Savannah & 2002 & Untreated & $25.2 \pm 0.1$ \\
Savannah & 2002 & Epoxiconazole & $36.9 \pm 1.0$ \\
Savannah & 2002 & Fluquinconazole & $21.0 \pm 0.1$ \\
Savannah & 2002 & Tebuconazole & $86.8 \pm 1.8$ \\
Savannah & 2003 & Untreated & $27.7 \pm 0.5$ \\
Hereward & 2004 & Untreated & $48.1 \pm 4.6$ \\
Consort & 2005 & Untreated & $54.5 \pm 2.0$ \\
Robigus & 2006 & Untreated & $56.7 \pm 5.8$ \\
\hline
\end{tabular}

*Frequency, mean of two measurements $\pm \mathrm{SE}$, was determined in allele-specific real-time PCR.

\section{DISCUSSION}

Analysis of the sensitivities of M. graminicola isolates in Rothamsted populations in 2003-06 revealed the expected disruptive selection towards a Qol-resistant population conferred by the predominance of a single mutation encoding substitution, G143A. By contrast, over the last 4 years, changes in the population towards decreased sensitivity to the azoles have been continuous, with new phenotypes ( $E C_{50}$ groupings) gradually emerging. This phenomenon is common when reduced sensitivity is mediated by several genes and/or mutations each contributing discretely to the final phenotype (Brent and Hollomon, 1998). Interestingly, between 2003 and 2004, a relatively large shift in median $\mathrm{EC}_{50}$ was measured for both epoxiconazole and tebuconazole (Fig. 1). A possible explanation is a hitch-hiking effect of Qol resistance selection. During this period a large proportion of the population carrying G143A was selected, with frequencies increasing from 40 to $80 \%$ (Table 2). It is plausible that a relatively large proportion of this subpopulation also carried the I381V substitution (see Fig. 4C).

I381V does not or only weakly confers reduced sensitivity to epoxiconazole, as $\mathrm{EC}_{50}$ distribution patterns for isolates carrying this substitution were similar to wild-type isolates (Fig. 4B). By contrast, a clear relationship between the presence of I381V and reduced tebuconazole sensitivity is apparent (Fig. 4C). Most isolates with I381V are less sensitive $\left(E_{50} \geq 1.0 \mathrm{mg} / \mathrm{L}\right)$, although other mechanisms undoubtedly also contribute to reduced tebuconazole sensitivity, as a few isolates without this alteration also have high $\mathrm{EC}_{50}$ values. The presence of $\Delta \mathrm{Y} 459 / \mathrm{G} 460$ did not seem to have a direct impact on the azole sensitivity of isolates.

Population studies confirmed the results of fungicide sensitivity tests. In comparison with untreated populations, increased mutation frequencies show that isolates carrying I381V were 

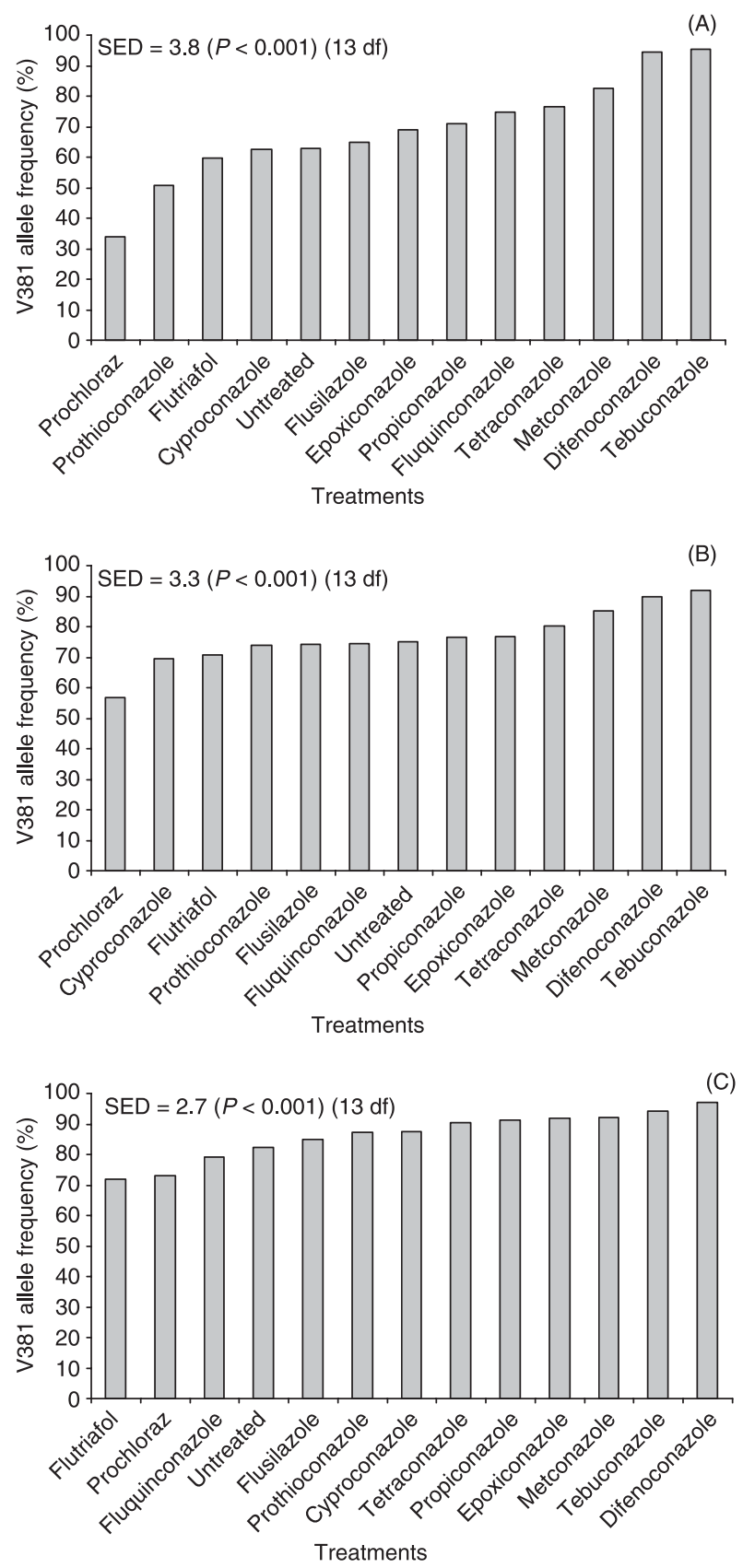

Fig. 5 Selection of I381V in untreated and azole-treated populations of M. graminicola sampled in Somerset (A), Herefordshire (B) and Norfolk (C).

selected in populations exposed to tebuconazole in all trials conducted during 2001-06 (Table 3 and Fig. 5). Results from the 2006 trial showed a clear difference in selection pressure for I381V for 12 azoles currently marketed in the UK. Strong selection for I381V was observed after application of tebuconazole, difenoconazole and, to a lesser extent, metconazole. For most other azoles, selection for I381V was either weak (e.g. epoxiconazole and tetraconazole) or absent (e.g. flutriafol and flusilazole).

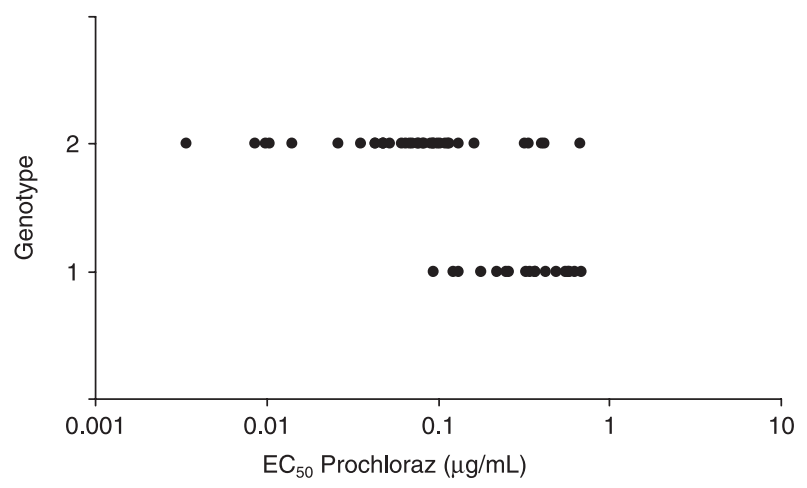

Fig. 6 Distribution of the CYP51 I381V substitution across prochloraz $\mathrm{EC}_{50}$ values of M. graminicola strains isolated in 2006. Genotypes 1 and 2 represent, respectively, 1381 (wild-type) and V381 CYP51 variants.

Interestingly, negative selection for this substitution was observed in populations treated with prochloraz.

Selection can be affected by differences in the intrinsic activity of azoles; however, Clark (2006) has shown, by comparing current and past field performance in the UK, that the azoles used in this trial were not affected to the same degree by resistance development. Differential selection of I381V between azoles may result from differences in side chain chemistry. Although selection of CYP51 alterations by azoles of varying side chain chemistries has not previously been reported, differences in the activity of azole derivatives against fungi of varying CYP51 secondary structure have been. For example, differences in the intrinsic activity of fluconazole against C. albicans and C. krusei (Fukuoka et al., 2003) are thought to result from CYP51 variation. Furthermore, divergent side chain structure is suggested to be responsible for the efficacy of ketoconazole and itraconazole against fluconazole-resistant C. albicans strains carrying substitution $\mathrm{Y} 132 \mathrm{H}$ (Sanglard et al., 1998). Therefore, as the residue equivalent to I381 in the crystal M. tuberculosis CYP51 protein, L321, is not only predicted to form a substrate recognition site, but also lies within $4 \AA$ of the heme-bound azole ligand (Podust et al., 2001), it seems reasonable to suggest interaction of this residue with the azole side chain.

The discovery that I381V correlates with a clear reduction in tebuconazole sensitivity and increased sensitivity to prochloraz may have implications for the use of these compounds in controlling M. graminicola populations as part of an anti-resistance strategy. However, in previous studies (Cools et al., 2005a; Stergiopoulos et al., 2003), a number of mechanisms, including overexpression of efflux pumps and multiple CYP51 amino acid changes, were proposed to confer decreased sensitivity to azoles. In view of the finding that $\mathrm{I} 381 \mathrm{~V}$ is not solely required for reduced tebuconazole sensitivity, let alone for reduced sensitivity to other azoles, monitoring of this substitution, although useful, is not a sufficiently robust diagnostic tool to predict potential control 
problems. Therefore, further functional studies are underway to determine not only the precise impact of I381V and other CYP51 alterations (e.g. alterations in codon region 459-461) on M. graminicola azole sensitivity but also their effect on intrinsic protein activity, and therefore fitness of isolates carrying these alterations.

\section{EXPERIMENTAL PROCEDURES}

\section{Fungal isolates}

Strains of $M$. graminicola were isolated from untreated fields at Rothamsted at the start of the season during 2003-06. The cultivars grown were Savannah (2003), Hereward (2004), Consort (2005) and Robigus (2006). Strains were derived from individual leaves sampled randomly with at least $5 \mathrm{~m}$ distance between each sampling point. Isolations of $M$. graminicola from plants were made according to Duncan and Howard (2000). Leaf pieces with lesions were placed on to sterile moist filter paper in up-turned Petri dishes and incubated at $23{ }^{\circ} \mathrm{C}$ overnight. Cirri, emerging from pycnidia, were collected using sterile forceps under a dissecting microscope and transferred into $0.5-\mathrm{mL}$ sterile microfuge tubes containing $30 \mu \mathrm{L}$ of sterile distilled water. Conidial suspensions were streaked on to antibiotic-amended yeast potato dextrose agar (YPD; ForMedium, Norwich, UK) amended with penicillin $\mathrm{G}$ sodium and streptomycin sulphate at $100 \mu \mathrm{g} /$ $\mathrm{mL}$, and incubated for 5 days at $23^{\circ} \mathrm{C}$. Single colonies subsequently grew in the form of yeast-like budding cells. Single spore isolates were propagated by transferring single colonies to fresh YPD plates. Isolates were either used directly in sensitivity assays or stored in $80 \%$ glycerol at $-80^{\circ} \mathrm{C}$.

\section{Fungicide sensitivity assays}

Sensitivity assays were carried out according to Pijls et al. (1994) with the following modifications. Wells of flat-bottomed microtitre plates (TPP 92696 test plates, Trasadingen, Switzerland) were filled with $100 \mu \mathrm{L}$ of liquid Czapek dox medium (Oxoid, Basingstoke, UK) amended with $60,20,6.7,2.2,0.74,0.25,0.08,0.027$, $0.009,0.003$ or $0.001 \mu \mathrm{g} / \mathrm{mL}$ of epoxiconazole, tebuconazole, prochloraz and azoxystrobin. Aliquots of $100 \mu \mathrm{L}$ of spore suspensions $\left(10^{5}\right.$ conidia/mL) of each $M$. graminicola isolate were added to each well. Plates were incubated for 4 days at $23^{\circ} \mathrm{C}$, and growth measured in an MRX plate reader (Dynex Technologies, Chantilly, VA) at $630 \mathrm{~nm}$. Fungicide sensitivities were determined as $50 \%$ effective concentration $\left(\mathrm{EC}_{50}\right)$ values calculated using a dose-response relationship.

\section{DNA extraction and quantification}

DNA was extracted from conidia and infected leaves as described previously by Fraaije et al. (1999). For extraction of DNA from plant samples containing more then ten leaves, a roller press (Pollähne, Wennigsen, Germany) was used as described by Rohel et al. (2002). DNA was quantified in flat-bottomed polystyrene 96-well microtitre plates using the fluorescent dye Thiazole Orange $(2.5 \mu \mathrm{m})$ (Aldrich Chemical Co., Milwaukee, WI). Fluorescence was measured at $530 \mathrm{~nm}$ with excitation at $485 \mathrm{~nm}$ using an Flx800 fluorimeter (Bio-Tek Instruments Inc., Winooski, VT). For testing leaf samples using real-time PCR, $50 \mathrm{ng}$ of 'total' (mix of plant and microbes) DNA was tested.

\section{Allele-specific real-time PCR}

To quantify pathogen target DNA and measure the frequency of Qol-resistant (A143) alleles in a single reaction, a previously developed PCR assay was used in which two primers and three probes act simultaneously (Fraaije et al., 2005b). The primer and probe sequences for this assay are presented in Table 1. For quantitative detection of substitution I381V and $\triangle Y$ Y459/G460 a similar approach was sought. Primers and probes (Table 1) based on TaqMan chemistry were designed with Primer Express Software (Version 7.1, Applied Biosystems, Foster City, CA) using the published CYP51 sequence (GenBank accession no. AF263470) as template. The probe design to detect $\Delta \mathrm{Y} 459 / \mathrm{G} 460$ was difficult due to sequence limitations, and therefore final probe sequences were provided through the Applied Biosystems Assays-by-Design Service, with primers designed using Primer Express Software (Table 1). The specificity of all primers and probes used in this study was further checked by BLAST nucleotide database searches and by testing against genomic DNA of wheat and several other cereal pathogens.

For all assays, $\mathrm{PCR}$ reactions were performed in $20-\mu \mathrm{L}$ reaction volumes (capped Thermo-Fast 96 PCR Plates; ABgene, Epsom, UK), consisting of $2.5 \mu \mathrm{L}$ DNA sample, $10.0 \mu \mathrm{L}$ Platinum ${ }^{\circledR}$ Quantitative PCR SuperMix-UDG (Invitrogen Life Sciences, Carlsbad, $\mathrm{CA}$ ) and $7.5 \mu \mathrm{L}$ sterile distilled water containing primers, probes and ROX reference dye (Invitrogen; $0.04 \mu \mathrm{L}$ per reaction). The final concentrations of the primers and probes in each assay are presented in Table 1. Reactions were carried out in an Mx3000P Real Time PCR System (Stratagene Europe, Amsterdam, The Netherlands) for 2 min at $50^{\circ} \mathrm{C}, 2$ min at $95^{\circ} \mathrm{C}$, followed by 50 cycles of $15 \mathrm{~s}$ at $95^{\circ} \mathrm{C}$ and $1 \mathrm{~min}$ at $60^{\circ} \mathrm{C}$. The increase in fluorescence from probes was measured at every temperature step and cycle during the reaction. For each sample in the cytochrome $b \mathrm{G} 143 \mathrm{~A}$ and CYP51 I381V assay, the threshold cycle (Ct, cycle at which the increase of fluorescence exceeded the background) for the Cy5-labelled probe was determined. Cleavage of this probe is correlated with the amount of total pathogen DNA as it binds independently of either $c y t b$ or CYP51 mutations. For each sample, the ratio of the mutant and wild-type genotypes, as measured by release of FAM and VIC fluorescence upon cleavage of the matching sequence, was measured five cycles after detection 
with the Cy5-labelled probe. Standard curves were generated by plotting known mutant genotype frequencies against signal ratios. Resulting regression equations were used to determine mutation frequencies in 'unknown' samples. Standards for measurement of mutation frequencies were included in each PCR run.

\section{Field trials and population survey samples}

For population samples, 25 leaves with symptoms were pooled. As well as sampling of untreated fields at Rothamsted during 2003-06, additional samples were available from previous experiments conducted at Rothamsted during 2001 (cv. Riband) and 2002 (cv. Savannah), in which single plots of $10 \times 3 \mathrm{~m}$ were left untreated or treated with three sprays of epoxiconazole (83 g/ha), fluquinconazole ( $83 \mathrm{~g} / \mathrm{ha})$, tebuconazole $(167 \mathrm{~g} / \mathrm{ha})$ and trifloxystrobin (167 g/ha) (see Fraaije et al., 2005a). Additional samples were received from field trials carried out by ADAS with cv. Consort in Taunton (Somerset, UK), Felton (Herefordshire, UK) and Terrington St. Clement (Norfolk, UK) (see Clark, 2006). A randomized block design, incorporating 12 treatments with four replicate plots of $24 \times 2 \mathrm{~m}$, was used. Plots were left untreated or sprayed twice with cyproconazole ( $80 \mathrm{~g} / \mathrm{ha})$, difenoconazole (75 g/ha), epoxiconazole (125 g/ha), flusilazole (125 g/ha), flutriafol (125 g/ha), fluquinconazole (125 g/ha), metconazole (90 g/ ha), prochloraz (405 g/ha), propiconazole (125 g/ha), prothioconazole $(200 \mathrm{~g} / \mathrm{ha})$, tebuconazole $(250 \mathrm{~g} / \mathrm{ha})$ and tetraconazole (125 g/ha) at GS 32 and 39. At least ten leaves of leaf 2 (leaf below flag) of each plot was sampled at random 3 weeks after the final spray and leaves of replicate plots were pooled together to obtain a population sample.

\section{Statistical analysis}

The significance of the effects of the different fungicide treatments on the frequency of I381V in populations was determined by ANova analysis using Genstat, 8th edition (VSN International Ltd, Hemel Hempstead, UK).

\section{ACKNOWLEDGEMENTS}

Part of this work was supported by Department of Environment, Food and Rural Affairs (Defra) through the Sustainable Arable LINK programme, project LK0976, in collaboration with HGCA, BASF, Bayer CropScience, DuPont, Syngenta, Velcourt, SAC and ADAS. The field trials in 2006, conducted by ADAS, were supported through additional funding from the Pesticides Safety Directorate (PSD) of Defra. Rothamsted Research receives grantaided support for the Biotechnology and Biological Sciences Research Council (BBSRC) of the UK. We gratefully acknowledge the Foreign and Commonwealth Office and Korean Ministry of Science and Technology for supporting S-H.K. through the British
Chevening/Korean Government Joint Scholarship. Thanks are also due to Dave Yeoman and colleagues for carrying out the field trials at the Rothamsted Farm and Rodger White for statistical analysis.

\section{REFERENCES}

Afonina, I., Zivarts, M., Kutyavin, I.V., Lukhtanov, E.A., Gamper, H. and Meyer, R.B. (1997) Efficient priming of PCR with short oligonucleotides conjugated to a minor groove binder. Nucleic Acids Res. 25, 2657-2660.

Albertini, C., Gredt, M. and Leroux, P. (2003) Polymorphism of $14 \alpha-$ demethylase Gene (CYP51) in the Cereal Eyespot Fungi Tapesia acuformis and Tapesia yallundae. Eur. J. Plant Pathol. 109, 117-128.

Brent, K.J. and Hollomon, D.W. (1998) Fungicide Resistance: the Assessment of Risk. FRAC Monograph no. 2. Brussels: GCPF.

Clark, W.S. (2006) Septoria tritici and azole performance. Fungicide resistance: are we winning the battle but losing the war? Aspects Appl. Biol. 78, 127-132.

Cools, H.J., Fraaije, B.A. and Lucas, J.A. (2005a) Molecular examination of Septoria tritici isolates with reduced sensitivities to triazoles. In: Modern Fungicides and Antifungal Compounds IV (Dehne, H.W., Gisi, U., Kuck, K.-H., Russell, P.E. and Lyr, H., eds), pp. 103-114. Alton, UK: BCPC.

Cools, H.J., Fraaije, B.A. and Lucas, J.A. (2005b) Molecular mechanisms correlated with changes in triazole sensitivity in isolates of $\mathrm{MycO}$ sphaerella graminicola. Proceedings of the BCPC Congress, Crop Science and Technology 2005, Vol. 1, pp. 267-274. Alton, UK: BCPC.

Cools, H.J., Ishii, H., Butters, J.A. and Hollomon, D.W. (2002) Cloning and sequence analysis of the eburicol $14 \alpha$-demethylase encoding gene (CYP51) from the Japanese pear scab fungus Venturia nashicola. J. Phytopathol. 150, 444-450.

Delye, C., Bousset, L. and Corio-Costet, M.F. (1998) PCR cloning and detection of point mutations in the eburicol $14 \alpha$-demethylase (CYP51) gene from Erysiphe graminis f. sp. hordei, a 'recalcitrant' fungus. Curr. Genet. 34, 399-403.

Delye, C., Laigret, F. and Corio-Costet, M.F. (1997) A mutation in the sterol $14 \alpha$-demethylase gene in Uncinular necator that correlates with resistance to sterol biosynthesis inhibitors. Appl. Environ. Microbiol. 63 , 2966-2970.

Duncan, K.E. and Howard, R.J. (2000) Cytological analysis of wheat infection by the leaf blotch pathogen Mycosphaerella graminicola. Mycol. Res. 104, 1074-1082.

Fraaije, B.A., Burnett, F.J., Clark, W.S., Motteram, J. and Lucas, J.A. (2005a) Resistance development to Qol inhibitors in populations of Mycosphaerella graminicola in the UK. In: Modern Fungicides and Antifungal Compounds IV (Dehne, H.W., Gisi, U., Kuck, K.-H., Russell, P.E. and Lyr, H., eds), pp. 63-71. Alton, UK: BCPC.

Fraaije, B.A., Cools, H.J., Fountaine, J., Lovell, D.J., Motteram, J., West, J.S. and Lucas, J.A. (2005b) The role of ascospores in further spread of Qol-resistant cytochrome $b$ alleles (G143A) in field populations of Mycosphaerella graminicola. Phytopathology, 95, 933-941.

Fraaije, B.A., Lovell, D.J., Rohel, E.A. and Hollomon, D.W. (1999) Rapid detection and diagnosis of Septoria tritici epidemics in wheat using a polymerase chain reaction/PicoGreen assay. J. Appl. Microbiol. 86, 701708.

Fraaije, B.A., Lucas, J.A., Clark, W.S. and Burnett, F.J. (2003) Qol resistance development in populations of cereal pathogens in the UK. 
Proceedings of the BCPC Congress, Crop Science and Technology 2005, pp. 689-694, Vol. 2. Alton, UK: BCPC.

Fukuoka, T., Johnston, D.A., Winslow, C.A., de Groot, M.J., Burt, C., Hitchcock, C.A. and Filler, S.G. (2003) Genetic basis for differential activities of fluconazole and voriconazole against Candida krusei. Antimicrob. Agents Chemother. 47, 1213-1219.

Gisi, U., Pavic, L., Stanger, C., Hugelshofer, U. and Sierotski, H. (2004) Dynamics of Mycosphaerella graminicola populations in response to selection by different fungicides. In: Modern Fungicides and Antifungal Compounds IV (Dehne, H.W., Gisi, U., Kuck, K.-H., Russell, P.E. and Lyr, H., eds), pp. 89-101. Alton, UK: BCPC.

Hamamoto, H., Hasegawa, K., Nakaune, R., Lee, J.L., Makizumi, Y., Akutsu, K. and Hibi, T. (2000) Tandem repeat of a transcriptional enhancer upstream of the sterol $14 \alpha$-demthylase gene (CYP51) in Penicillium digitatum. Appl. Environ. Microbiol. 66, 3421-3426.

Hardwick, N.V., Jones, D.R. and Royle, D.J. (2001) Factors affecting diseases of winter wheat in England and Wales, 1989-98. Plant Pathol. 50, 453-462.

Joseph-Horne, T. and Hollomon, D.W. (1997) Molecular mechanisms of azole resistance in fungi. FEMS Microbiol. Lett. 49, 141-149.

Marichal, P., Koymans, L., Willemsens, S., Bellens, D., Verhasselt, P., Luyten, W., Borgers, M., Ramaekers, F.C.S., Odds, F. and Vanden Bossche, H. (1999) Contribution of mutations in the cytochrome P450 $14 \alpha$-demethylase (Erg11p, Cyp51p) to azole resistance in Candida albicans. Microbiology, 145, 2701-2713.

Perea, S., Lopez-Ribot, J.L., Kirkpatrick, W.R., McAtee, R.K., Santillan, R.A., Martinez, M., Calabrese, D., Sanglard, D. and Patterson, T.F. (2001) Prevalence of molecular mechanisms of resistance to azole antifungal agents in Candida albicans strains displaying high-level fluconazole resistance isolated from human immunodeficiency virusinfected patients. Antimicrob. Agents Chemother. 45, 2676-2684.

Pijls, C.F.N., Shaw, M.W. and Parker, A. (1994) A rapid test to evaluate in vitro sensitivity of Septoria tritici to flutriafol, using a microtitre plate reader. Plant Pathol. 43, 726-732.

Podust, L.M., Poulos, T.L. and Waterman, M.R. (2001) Crystal structure of cytochrome P450 14 $\alpha$-sterol demethylase (CYP51) from Mycobacterium tuberculosis in complex with azole inhibitors. Proc. Natl Acad. Sci. USA, 98, 3068-3073.

Rohel, E.A., Laurent, P., Fraaije, B.A., Cavalier, N. and Hollomon, D.W. (2002) Quantitative PCR monitoring of the effect of azoxystrobin treatments on Mycosphaerella graminicola epidemics in the field. Pest Manag. Sci. 58, 248-254.

Sanglard, D., Ischer, F., Koymans, L. and Billie, J. (1998) Amino acid substitutions in the cytchrome P450 lanosterol 14 $\alpha$-demethylase (CYP51A1) from azole-resistant Candida albicans clinical isolates contribute to resistance to antifungal agents. Antimicrob. Agents Chemother. 42, 241-253.

Schnabel, G. and Jones, A.L. (2000) The $14 \alpha$-demethylase (CYP51A1) gene is overexpressed in Venturia inaequalis strains resistant to myclobutanil. Phytopathology, 91, 102-110.

Stergiopoulos, I., Van Nistelrooy, J.G.M., Kema, G.H.J. and De Waard, M.A. (2003) Multiple mechanisms account for variation in base-line sensitivity to azole fungicides in field isolates of Mycosphaerella graminicola. Pest Manag. Sci. 59, 1333-1343.

Wyand, R.A. and Brown, J.K.M. (2005) Sequence variation in the CYP51 gene of Blumeria graminis associated with resistance to sterol demethylase inhibiting fungicides. Fungal Genet. Biol. 42, 726-735.

Zhan, J., Stefanato, F. and McDonald, B.A. (2006) Selection for increased cyproconazole tolerance in Mycosphaerella graminicola through local adaptation and response to host resistance. Mol. Plant Pathol. 7, 259-268.

Zwiers, L.-H., Stergiopoulos, I., Van Nistelrooy, J.G.M. and De Waard, M.A. (2002) ABC transporters and azole sensitivity in laboratory strains of the wheat pathogen Mycosphaerella graminicola. Antimicrob. Agents Chemother. 46, 3900-3906. 